\title{
The Formation and Folk Implication of Dragon Dance in Hong'an, Hubei
}

\author{
Ming Chen ${ }^{1, *}$ \\ ${ }^{1}$ Huanggang Normal University, Huanggang, Hubei 438000, China \\ *Corresponding author.Email:16113917@qq.com
}

\begin{abstract}
Hong'an dragon dance in Hubei presents folk customs and beliefs in an artistic way, which enjoys high folk and artistic value. To investigate the way that the custom integrates into local people's daily life, the methods of induction and data collection are employed to demonstrate the formation, folk implication and artistic value of dragon dance in Hong'an, Hubei. The results show its formation can be explained by multiple factors. The identity of traditional culture, belonging, and national cohesion reflect the folklore implication that symbolizes auspiciousness, disaster elimination and blessing, implies the traditional consciousness of group psychology and the utilitarian goal, and accumulates the deepest spiritual pursuit and aesthetic taste of the masses.
\end{abstract}

\section{Keywords: Hong'an, dragon dance, folk implication, cultural function, artistic value}

\section{INTRODUCTION}

Dragon dance, a traditional festival, is also known as "dragon lantern" and so on with long history and profound meaning. In Hong'an, every year from the first day to the fifteenth day of the first lunar month, or festivals, witness people beating gongs and drums and playing dragon dance. The sound of firecrackers, singing, laughing makes the atmosphere more lively. Dragon lanterns in Hong'an are rich in variety. The ones made of straw are grass dragons, those made of bamboo are stick dragons, those made of cloth are cloth dragons, and those connected by a bench are bench dragons. Dragon lanterns in different regions have their own characteristics.

The dragon-shaped prop in Qiliping, Hong'an, Hubei, presents in two forms: rolling lamp and red lamp. It is composed of dragon head, dragon body and dragon tail. It is mainly made of bamboo sticks, wooden racks, iron wires, paper made to resemble money and burned as an offering to the dead, silk and native cloth, etc. There is a candlelight inside the red lamp. In terms of the craftsmanship, the dragon head is the most exquisite. It is made of bamboo sticks. The neck, forehead, mouth, horns are made of bamboo sticks, and then covered with paper burned as an offering to the dead. Different parts are painted with different colors to highlight features and make dragon

*Fund: This paper is the phased achievement of the Humanities and Social Sciences Project of the Department of Education of Hubei (project number: 14G407), as well as the phased achievement of the Youth Research Project of Huanggang Normal University (project number: 2013025703). head more colorful and vibrant. In view of the large amount of activity, the dragon head should be light, less than 3 kilograms commonly. Tie them tight so they don't fall off when they're dancing. The production of dragon body is relatively simple, with bamboo wood and iron wire woven into cylinders, about $60 \mathrm{~cm}$ long and $33 \mathrm{~cm}$ in diameter. The handle at the lower end is about 1 meter long. Then sew "clothes" on it, which is dragon skin. Dragon skin is generally made of dyed homespun cloth, and the knots are connected and fixed with ropes. The tail of the dragon is small and flexible with a horn-like form and fan-shaped ends, which is more conducive to the changes in the dancing speed and movement of the tail.

\section{THE FORMATION OF DRAGON DANCE IN HONG'AN, HUBEI}

Hong'an county did not go well in the early days, with many natural and man-made calamities. At the same time, it had to face foreign wars. From the end of Ming Dynasty to the end of Qing Dynasty, the county with short history is involved in almost every peasant uprising, warlord dogfight. The able people built walls and fortresses based on their surnames to defend themselves against foreign enemies, while the unable people fled from their homes. To get rid of such drifting life and heal the pain caused by wars, the villagers played with dragon lanterns, which is a symbol of auspiciousness and dignity with the intention of eliminating disasters and bringing good fortune. They prayed that the dragon could bring good fortune and provide them with spiritual comfort and courage. 
The dragon dance in Qiliping, Hong'an, Hubei is organized by religious organizations. The clan leaders, serving as the organizers, are responsible for funding and effort, while the villagers for performing. In Qiliping town, there is a principle that dragon dancers must be villagers in Zhangjiawan. The performers indulged in various styles and techniques of dragon dancing. There are mainly several kinds of flower fair performances, such as rowing oars and women's boat rides. After the Huang'an-Macheng uprising, the dragon dance was interrupted.

The founding of the People's Republic of China didn't bring back everything that people experienced and lost in the war. The memory is lingering in their hearts. Their spiritual trauma will not be healed with the finish of wars, and post-war policies for the benefit of the people. Faced with a poor life and dilapidated homeland, people think of dragon dance for wishing, and the town of Qiliping in Hongan, Hubei province has always had the tradition of dragon dance. In 1958, thanks to the organization of the village committee, the first Dragon Lantern Festival was held to convey to the dragon their inner prayer: in the coming year, good weather will be brought about, diseases will be warded off, and a stable life will be lived. In addition to traditional dragon dance, there are other performances at the Dragon Lantern Festival. When the dragon lantern is parading around the village, the remaining people can stay and watch traditional flower fairs, shadow puppets and so on. The performance, while retaining its original form, combined with the social situation at that time, adapted the content of lyrics and changed the roles of actors. It is said that shadow puppetry also has the function of redeeming a vow to a god. A total of six Dragon Lantern Festivals were held in Qiliping Town, Hong'an, Hubei. For each event, the villagers need to spend more than half a year to prepare. Moreover, the Hong'an dragon dance has the custom of "one dance for three years", so dragon lantern festivals were also held in 1959 and 1960. Later, due to the "Rectification Movement" and the "Cultural Revolution", the dragon dance once again stagnated.

Since the Third Plenary Session of the Eleventh Central Committee of the Communist Party of China was held in 1978, reforms have been in full swing in Hong'an, Hubei. A thriving rural economy has emerged. After the $1980 \mathrm{~s}$, many villages began to organize Spring Festival entertainment activities. Zhangjiawan village held two dragon lantern fairs in 1983 and 1985. In addition to the traditional performances at the Dragon Lantern Festival, there are also more shows. On the first day of the first lunar month, when families have just let off firecrackers and send New Year's greetings to each other, there will be numerous "paper dragons", "cloth dragons" and "grass dragons" traveling from house to house in the streets with noisy gongs and drums. Sometimes they would walk around the hall, and the villagers would show their gratitude in different ways, such as setting off firecrackers and giving candy or cigarettes. During this period, the biggest difference of the Dragon Lantern Festival was that people's thoughts had also been greatly changed in the context of reforms. The most prominent manifestation was that women were on the stage as the main performer.

After entering the 21st century, in 2005 and 2006, Zhangjiawan Village, Qiliping Town, Hong'an, Hubei hosted two dragon lantern festivals. Thanks to the organization of the Lantern Committee, everyone pays money and makes efforts to organize the Lantern Festival spontaneously. The scale of Dragon Lantern Festival is far bigger than that in the 1980s. This time, two more rolling lamps and two sets of gongs and drums have been added. Traditional performances, such as red lamps, carts and lotus gathering boat, have been retained.

\section{THE FOLKLORE IMPLICATION OF THE DRAGON DANCE IN HONG'AN, HUBEI}

\section{A. Symbol of auspiciousness and dignity}

Dragon is not only in China, but also in the fairy tales of many countries in the world. However, the dragon in western countries is often the representative of evil forces, while that in China a symbol of good luck and dignity. In ancient times, the emperor was called the "the rightful king", the clothes worn by the emperor "dragon robes", and the fetuses carried by the emperor's concubines "dragon fetuses", etc. It can be seen that the dragon is a noble symbol in China. Moreover, dragons in China are very capable: flying in the air, going for a dive under the ocean, making clouds and bringing rain, eliminating disasters and diseases, etc. All good wishes are placed on the dragon. They worship the dragon and pray for the protection of the dragon. This is the totem worship with the dragon as a totem.

According to Ciyuan, dragon is a mysterious animal in ancient legends that can change in shapes, make clouds and bring rain, and benefit all things. It is the superior one among worm drake. It also serves as a totem of the Han nation and a symbol of the Chinese nation. The Classics of Mountains and Seas records that 东海中有流坡山，入海千里，其上有兽，状如牛......黄帝得之， 以其皮为鼓，橛以雷兽之骨，声闻五百里，以威天下 (There is a sloping hill in the East China Sea, which boasts sacred animals that looked like oxen. But it was skinned and shaved by the Yellow Emperor, who made drums out of its skin and drumsticks out of its bones. The sound of this drum can travel $500 \mathrm{li}$, enough to terrify the whole world). Since then, the emperor was invincible, and the dragon gradually became the totem of the tribal alliance. Later, people in ancient times took 
dragon, phoenix, unicorn, and tortoise the four spirits, and the children of the Chinese nation were called the descendants of the dragon, giving the dragon a noble and prominent status. In the long historical process, the image of the dragon has undergone continuous changes and development. The image of the dragon as we know it today combines the characteristics of various animals, namely tortoise eyes, antlers, ox beak, dog nose, catfish whiskers, lion mane, snake tail, fish scales and eagle claws. Meanwhile, various virtues and excellent qualities are endowed on dragon. In ancient legends, the dragon is powerful, brave and good at fighting. It can relieve all the people's difficulties and sufferings. It is brave, flexible, friendly and noble in one and the embodiment of people's good wishes, gathering the people's ideals, wishes, wisdom and strength, symbolizing luck and nobility.

\section{B. Symbol of eliminating evil and bringing fortune}

Dragon dance originated from ancient sacrificial activities. In ancient times, there was no scientific explanation for the natural state of thunder, lightning, sickness and death, and there was always the belief that some kind of deity was at work. In order to protect the lives of themselves and the tribe and keep the race alive, people mentally imagined "dragon". When everyone believed this statement, the "dragon" was gradually endowed with various powers. When people encounter disasters such as drought and plague, related sacrificial rituals will be held in the temple to pray for the dragon king to rain and alleviate the disaster. In this sacrificial ritual, the shaman would imitate the state of the dragon, whirl and dance, and gradually develop into the current dragon dance.

Hong'an, Hubei is located at the southern foot of the Dabie Mountains in the northeast of Hubei, the junction of Hubei and Henan provinces. It is a typical mountainous agricultural county. Qiliping Town, 23 kilometers north of Hong'an County, Hubei, is the largest town in Hong'an and a famous historical and cultural town in China. The town has an area of 362 square kilometers, a total population of 98,000, and 69 administrative villages. It borders Xinxian County of Henan Province to the north, Dawu County to the west, Macheng City to the east, and Huolian to the south. Tiantai Mountain, a famous peak in northeastern Hubei, is located in the north of the town. There are two major tributaries of the Yangtze River, namely Jushui and Daoshui. The mountain area is $320,000 \mathrm{mu}$, suitable for the growth of various economic crops and trees. In history, it was known as "Three Stores", "Sanghuai Tree", and "Three Bridges". It is surrounded by mountains and faces water on three sides. Located on the convex bank of the bend of Daoshui, it is the distribution center of all kinds of goods from the north mountain area of Hongan County to other areas. The vital position of "dominating the central Plains and overlooking the South of the Yangtze River" made it a contested place for the military strategist. Not only did the people believe in the existence of the dragon and accept it as the god in charge of water, but they also believed that there were dragons in the mountains, which were cultivated by animals in the mountains. What's the reason for that? Hong'an is surrounded by mountains and water, and often suffers from mountain torrents, which should be a natural phenomenon. However, the torrential rain rushing down from the mountain stream and the surging river on the riverbed will remind people of the shape of dragon. It is well known that dragons are imaginary, and generally have some basis in reality. The people of Hong'an will believe that there are dragons in the water and in the mountains, which are inseparable from their real life. First, it reflects their inner needs, hoping that a capable and mindful god like dragon can help them overcome worries, disasters, and bring blessings. Second, it reveals the simple, strong, and brave personality of the mountain people.

\section{THE ARTISTIC VALUE OF DRAGON DANCE IN HONG' AN, HUBEI}

Dragon Dance in Hong'an, Hubei is a collection of folk activities and folk songs and dances. The design and production of dragon-shaped props, the dragon dance ceremony including "receiving - out - sending", and theatrical performances after the ceremony, etc. are inseparable part of dragon dance culture with rich and profound national cultural heritage. It is the reflection of Hong'an traditional culture and the embodiment of the simple, strong and brave personality of the people of Hong'an. The development of times and economy has promoted that of dragon dance culture. The exquisite dragon-shaped props, the supreme dragon dance skills, the cooperation of music and skills, people's practice, performance and appreciation, proud of the heritage of dragon dance further proves artistic value.

Dragon dance is a sport that is coordinated by many people with music and accompaniment. It not only enjoys high artistic appreciation value, but also exercises people's physique and strengthens people's will. Located in the middle reaches of the Yangtze River, Hong'an, Hubei is a cross-region of regional culture. The dragon dance custom has both the soft and beautiful characteristics of the southern style and the rough and fortitude aesthetic characteristics of the northern style. The dragon dance in Hong'an, Hubei is divided into "red lamp" and "rolling lamp" with the former include red candle. Without much technical skill, but the dragon boasts a dignified manner, big eyes, and divine nobility. The "rolling lamp" is made of cloth, using the three primary colors of red, yellow and blue to finely restore the dragon in people's hearts. 
Dragon dancers wearing colorful cloth on their heads, silk and satin, and thin boots on their feet showed various forms of dancing such as "flood dragon out of water" and "surging river and jumping sea" in the dances of sweeping, waving, bending, leaning and running with their light, flexible and neat dragon dance routines. The dragon's expression and majesty were shown incisively and vividly, and people's reverence for the gods and joy of the festival were also expressed. Dragon dance is a sport of team cooperation. Only in the case of concerted efforts, can dragon dancers dance the charm and the momentum of the dragon, inspire people's inner national superiority, and enable people to unite as one and contribute to the construction of hometown.

The dragon dance ceremony is followed by artistic performances. The performances are mainly local folk songs and dances, such as tea picking songs, bamboo riding, lotus playing, etc. The simple performance of the villagers shows the wisdom of the local people, the precious heritage left by the ancestors, and also reflects the local people's spirit of unity, striving to make progress.

\section{CONCLUSION}

The modern dragon dance, a traditional national sports, is no longer a simple ritual of praying for rain, but cultural sports activities incorporating various concepts such as competition and fitness, which have embarked on the track of internationalization and standardization. Within a certain place and a period of time, the dragon dance competition is carried out by dragon dancers through the changes of walking, running, jumping, tumbling, rolling and other movements combined with the dragon dance skills with the accompaniment of drum music. Given its identity as traditional national movement, it should be further tapped into for folk culture and cultural value, contributing more to the development and innovation of modern dragon dance.

\section{References}

[1] Zhang Xiaoshu. A Study on the Dragon Dance of Hong'an Zhangjiawan Hubei [D]. Central China Normal University. (in Chinese)

[2] Bai Jiawei. An Analysis in the Identity of Ethnic of the Rural Area: A Case study of custom of dragon dance in Baijiadawan, Northern Hubei [D]. Central China Normal University, 2013.5. (in Chinese)

[3] $\mathrm{Hu}$ Min. Chongqing Tongliang Dragon Dance Status Quo and Development Countermeasures [D]. Southwest University, 2011.6. (in Chinese)

[4] Yuan Xiaoling. Study on the Living Situation and Development Strategy of Xuefeng "Broken Neck Dragon" [D]. Jishou University, 2011.3. (in Chinese)
[5] Zhang Bin. Succession and Innovation of Chinese Traditional Dragon-Brandish from a Perspective of Immaterial Cultura Heritage [D]. Hu'nan Normal University, 2008.5. (in Chinese)

[6] Li Lan. The Study of Sichuan Mianzhu New Year Pictures Change in Social Function [D]. Sichuan Normal University, 2015.4. (in Chinese)

[7] Li Yufeng. Investigation of the Value of Holding Dragon Dance in Colleges in the Perspective of the Function of Colleges: Taking Nanjing University of Science and Technology as an Example [D]. Nanjing Sport Institute, 2012.6. (in Chinese)

[8] Tan Lidi. Research on Presentation and Utilization of the Revolutionary Site's Buildings in Qiliping Town of Hong'an [D]. Huazhong University of Science and Technology, 2019.7. (in Chinese) 